Удк 615,32:547.918:616.61]:001.8

\title{
ОПРЕДЕЛЕНИЕ СОДЕРЖАНИЯ АРБУТИНА В ПРОТИВООКСАЛАТНОМ СБОРЕ НА ОСНОВЕ ЛЕКАРСТВЕННЫХ РАСТЕНИЙ ДАЛЬНЕГО ВОСТОКА
}

\author{
() Е.В. Загузова, Т.А. Степанова, Н.А. Цимбалист" \\ Дальневосточный государственный медицинский универсuтеm,
ул. Муравьева-Амурского, 30, Хабаровск, 680000 (Россия), e-mail: kfnat@yandex.ru
}

Приведены материалы по разработке методики количественного определения арбутина в сборе противооксалатном. В качестве метода анализа арбутина выбрана высокоэффективная жидкостная хроматография, так как широко известные методы определения арбутина - йодометрия и спектрофотометрия являются недостаточно селективными для анализа растительных препаратов, особенно таких многокомпонентных, как лекарственные сборы.

В ходе разработки методики с использованием метода ВЭЖХ экспериментально обоснованы условия пробоподготовки и хроматографирования. При выборе экстрагента установлено, что предпочтение следует отдать 70\%-ному этиловому спирту, а для очистки извлечения наиболее рационально использовать колоночную хроматографию на оксиде алюминия.

Проведен сравнительный анализ и статистическая оценка результатов определения арбутина по фармакопейной, спектрофотометрической и ВЭЖХ методикам. Показано, что разработанная методика характеризуется относительно высокой избирательностью, точностью и пригодна для стандартизации сбора противооксалатного по содержанию арбутина. Установлено, что применение спектрофотометрической методики дает завышение, а фармакопейной методики - занижение результатов по сравнению с использованием оригинальной методики.

С помощью разработанной методики определено содержание арбутина в опытно-промышленных сериях сбора. Обоснован норматив содержания арбутина в сборе при серийных анализах: его количество в сборе противооксалатном должно быть не менее $0,9 \%$.

Ключевые слова: ВЭЖХ, арбутин, сбор противооксалатный.

\section{Введение}

В Дальневосточном государственном медицинском университете разработан сбор для лечения оксалатных нефропатий на основе лекарственных растений Дальнего Востока: лимонника китайского, брусники, калины Саржента и др. [1]. Разработка лекарственных средств из растительного сырья требует тщательного изучения вопросов их стандартизации. Стандартизация сырья по содержанию действующих веществ, обеспечивающих фармакологическую активность, является наиболее объективной и отвечает современным требованиям.

Целью настоящей работы является определение и обоснование нормативов содержания фармакологически активного соединения арбутина, который содержится в таких сырьевых компонентах сбора, как листья брусники и плоды калины [2] Арбутин обладает антиоксидантным, противовоспалительным, антимикробным и мочегонным действием, что имеет значение при лечении мочекаменной болезни [3-5]. Таким образом, количественное определение арбутина в сборе представляется актуальной задачей.

\footnotetext{
Загузова Елена Владимировна - старший преподаватель кафедры фармакогнозии и ботаники, e-mail:dfk.07@mail.ru

Степанова Татьяна Алексеевна - заведующая кафедрой фармакогнозии и ботаники, доктор фармацевтических наук, тел. (4212) 32-64-26

Цимбалист Наталья Анатольевна - доцент кафедры фармакогнозии и ботаники, кандидат фармацевтических наук, тел. (4212) 32-64-26, e-mail: kfnat@yandex.ru
}

В литературе встречаются различные методы количественной оценки арбутина в растительном сырье: фармакопейный метод йодометрического титрования [6]; фотоэлектроколориметрический, в основе которого лежит реакция арбутина с диазореактивом [7]; спектрофотометрический (СФМ), основанный на конденсации арбутина с 4-аминоантипирином в щелочной среде в присутствии

\footnotetext{
* Автор, с которым следует вести переписку.
} 
окислителя [8]; спектрофотометрический метод, основанный на осаждении сопутствующих арбутину веществ свинца ацетатом основным и спектрофотометрированием фильтрата при длине волны 281 нм [9]; хроматоспектрофотометрический, основанный на применении алюминия оксида для очистки арбутина от сопутствующих примесей [8], метод высокоэффективной тонкослойной хроматографии с денситометрическим детектированием [10], метод высокоэффективной жидкостной хроматографии (ВЭЖХ) с УФ и флюориметрическим детектированием [11-13].

В указанных методиках непосредственному определению арбутина предшествуют различные способы очистки от сопутствующих веществ. Чаще всего применяется осаждение полифенольных соединений свинца ацетатом и колоночная хроматография на алюминия оксиде $[8,14,15]$. Естественно, на количественное определение арбутина влияет способ очистки от сопутствующих веществ. Осаждение полифенолов свинца ацетатом приводит к потерям арбутина, однако потери арбутина, по мнению ряда исследований, возможны и при хроматографической очистке $[8,15]$.

Фармакопейная методика определения арбутина имеет ряд недостатков. В первую очередь, это низкая специфичность, которая является причиной завышенных результатов, поскольку после осаждения полифенольных соединений раствором свинца ацетата основного в извлечении остаются вещества, способные легко окисляться йодом (гидрохинон, катехины, аскорбиновая кислота и др.). При титровании раствором йода точка эквивалентности устанавливается визуально по изменению окраски индикатора, что может привести к ошибке. Кроме того, фармакопейный метод определения арбутина трудоемкий и длительный.

По литературным данным, наиболее объективные результаты достигаются при использовании хроматоспектрофотометрического метода определения арбутина, так как при хроматографировании извлечения на колонке с алюминия оксидом происходит более полная очистка арбутина от сопутствующих фенольных соединений. Метод предполагает получение спиртового извлечения из сырья (40- или 70\%-ным этиловым спиртом в зависимости от объекта исследования) и дополнительную хроматографическую очистку арбутина от сопутствующих веществ на алюминия оксиде. Оптическую плотность очищенного элюата измеряют на спектрофотометре при длине волны $(284,285,287$ нм) в сравнении со стандартом (арбутином или гидрохиноном) $[8,14,16]$. Результаты определения арбутина данным методом, представленные в работе [17], показали, что он тоже может давать завышенные значения вследствие неполной очистки сложной многокомпонентной смеси.

В нашем случае объектом исследования является многокомпонентная смесь растительного сырья, характеризующаяся сложным химическим составом. Поэтому для оценки арбутина в сборе мы выбрали на сегодняшний день наиболее селективный метод - высокоэффективную жидкостную хроматографию.

\section{Экспериментальная часть и обсуждение результатов}

Хроматографические исследования проводили на хроматографе «Agilent Technologies 1100 Series», снабженном градиентным насосом Agilent 1100, термостатом А 1100, устройством А 1100 для введения образцов и спектрофотометрическим детектором, с использованием колонки Zorbax SB C 18, 4,6×250 мм с размером частиц 5 мкм, скорость подачи элюента 1 мл/мин. Аналитическая длина волны - 285 нм, объем пробы - 20 мкл, температура колонки - $25^{\circ} \mathrm{C}$, продолжительность хроматографирования - 20 мин, подвижная фаза - вода : ацетонитрил : уксусная кислота (164: $36: 2)$. В этих условиях время удерживания

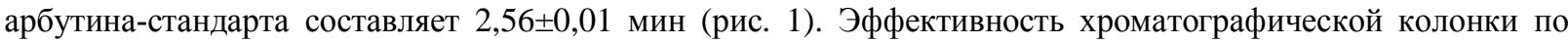
пику арбутина-стандарта составляет не менее 5500 теоретических тарелок.

Хроматографический анализ спиртового извлечения сбора показал наличие пика исследуемого вещества, сходного по времени удерживания с пиком стандарта-арбутина (2,56 мин), что в целом и явилось основанием к разработке методики (рис. 2).

В фармакопейной методике в качестве экстрагента используется вода, в различных описанных методиках - вода, 40- и 70\%-ный этиловый спирт, поэтому были опробованы указанные экстрагенты по отношению к изучаемому объекту. Экстракцию водой осуществляли по фармакопейной методике, аналогичную схему экстракции применили для 40- и 70\%-ного этилового спирта. Полученные извлечения очищали от сопутствующих веществ двумя способами: осаждением раствором свинца ацетата основного и хроматографией на колонке с алюминия оксидом нейтральным. В первом случае после коагуляции осадка извлечение фильтровали, во втором - элюат собирали в колбу. Полученные таким образом фильтрат и элюат упаривали на ротационном испарителе досуха и остаток переносили количественно соответствующим растворителем в мерную колбу на 25 мл. При этом получали мутные растворы, которые подвергали центрифугированию при 5000 об/мин в течение 30 мин. Надосадочную жидкость использовали для количественного измерения. Количественное содержание арбутина определяли методами ВЭЖХ и спектрофотометрии. 


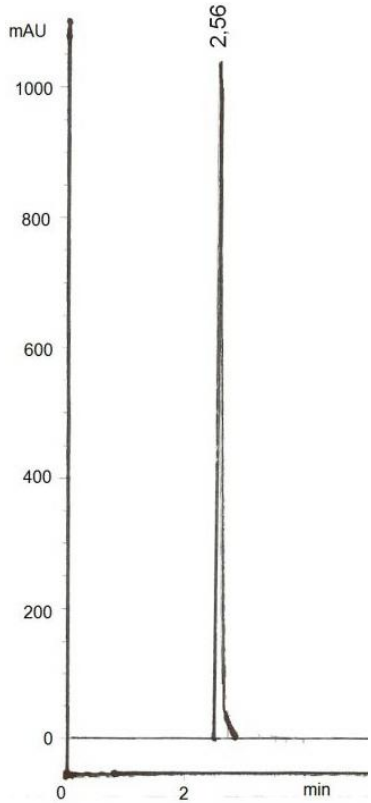

Рис. 1. Хроматограмма раствора ГСО арбутина

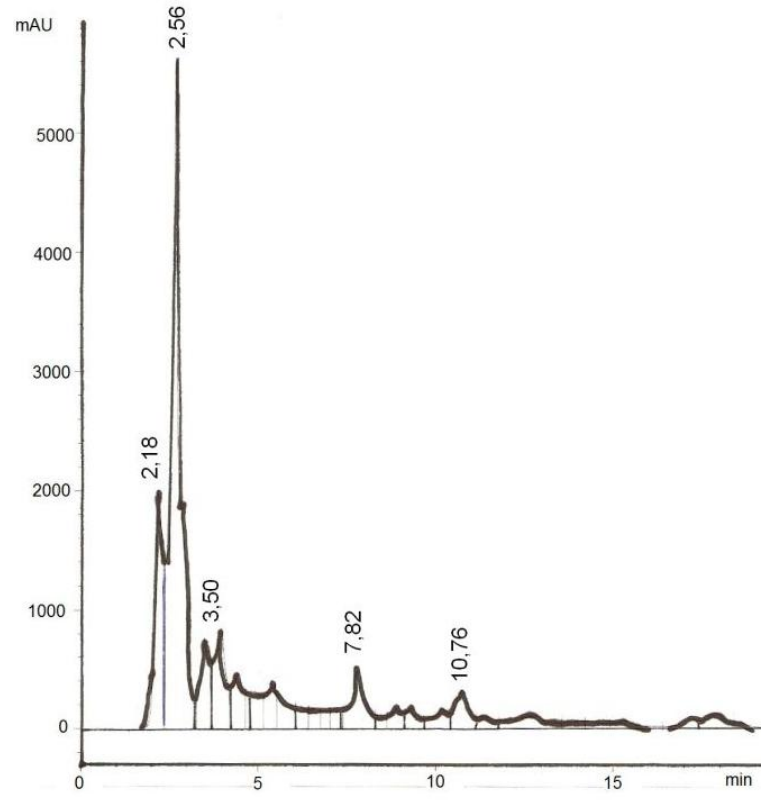

Рис. 2. Хроматограмма спиртового извлечения сбора

Для спектрофотометрии готовили разведение полученных растворов в соотношении $1: 50$, в качестве раствора сравнения использовали соответствующий растворитель (вода, 40-, 70\%-ный этиловый спирт).

Предварительно получили спектры раствора арбутина - стандарта $(0,05 \%)$, извлечения из сбора и извлечений, очищенных двумя способами. Как видно на рисунке 3, очисткой достигается значительное уменьшение интенсивности оптической плотности раствора и максимум II полосы поглощения имеет более симметричную форму. При этом положение максимума извлечения из сбора находится в пределах 279280 нм, его очищенных извлечений - 280-281 нм, максимум раствора арбутина - стандарта приходится на 284 нм. В целом, полученная спектральная картина может говорить о неполной очистке арбутина в сборе от сопутствующих веществ при использовании обоих способов. Оптическую плотность очищенных извлечений измеряли при $\lambda=284$ нм, соответствующей максимуму поглощения арбутина-стандарта, в кювете с толщиной слоя 1 см.

Результаты анализа показали, что экстрагенты обладают примерно одинаковой извлекающей способностью по отношению к арбутину (табл. 1). При этом установлено, что очистка извлечения от сопутствующих веществ свинца ацетатом по сравнению с хроматографической очисткой влечет снижение количества арбутина: при определении методом ВЭЖХ - на 22\%, спектрофотометрическим методом - на $27 \%$. Это значит, что очистка с использованием колоночной хроматографии на алюминия оксиде является более рациональной. Следует отметить, что извлечения, полученные с использованием воды и 40\%-ного этилового спирта, представляли собой мутные растворы и медленно проходили через колонку с алюминия оксидом, что объясняет предпочтение, отданное 70\%-ному этиловому спирту в качестве экстрагента.

На следующем этапе было изучено влияние кратности экстракции на выход арбутина. Двухкратную экстракцию проводили порциями по 50 и 25 мл 70\%-ного этилового спирта, трехкратную - порциями по 50, 25 и 20 мл экстрагента. Извлечения фильтровали в мерную колбу на 100 мл, сырье в колбе промывали и объединяли извлечения. Сравнение результатов двухкратной $(3,08 \pm 0,13)$ и трехкратной экстракции $(2,97 \pm 0,08)$ показало отсутствие между ними достоверных различий $\left(\mathrm{t}_{\text {эксп }}=0,8, \mathrm{t}_{\mathrm{kp}}=2,3\right)$. Следовательно, можно проводить двухкратную экстракцию. Дополнительно для проверки истощения сырья была проведена третья экстракция 20 мл 70\%-ного этилового спирта. В результате было выявлено, что содержание арбутина в последней порции экстракта составляет 0,005\%, что не оказывает значимого влияния на результаты определения арбутина в сборе.

После выбора способа очистки экстрагента и кратности экстракций была проведена очистка извлечения на колонке с алюминия оксидом, при этом использовали сорбент, нейтральный для хроматографии. Хроматограмма элюата, представленная на рисунке 4, говорит об удовлетворительной очистке извлечения из сбора по сравнению с исходным. Дополнительная проверка на возможность потерь арбутина на колонке показала, что в выбранных условиях проведения очистки извлечения, описанных ниже, потерь арбутина на алюминия оксиде не наблюдается. 
Рис. 3. УФ-спектр спиртового извлечения сбора (1), элюата (2), фильтрата (3) и раствора арбутина (4)

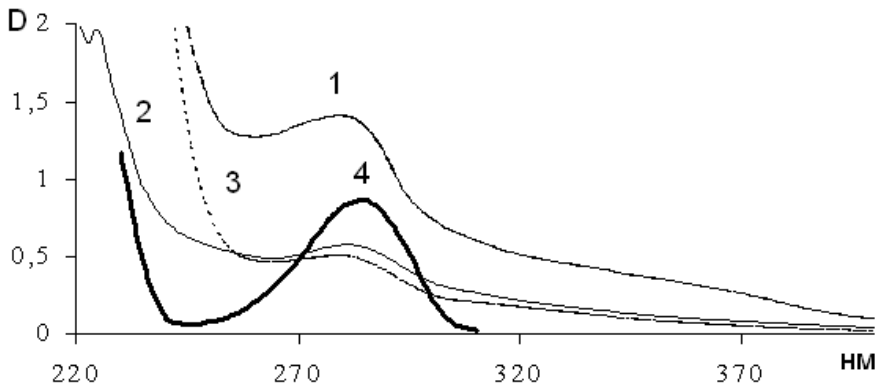

Таблица 1. Содержание арбутина в сборе противооксалатном при разных условиях пробоподготовки

\begin{tabular}{l|c|c|c|c}
\hline \multirow{2}{*}{\multicolumn{1}{c|}{ Экстрагент }} & \multicolumn{4}{|c}{ Содержание арбутина, \% } \\
\cline { 2 - 5 } & \multicolumn{2}{|c}{ хроматография на оксиде алюминия } & \multicolumn{2}{c}{ осаждение ацетатом свинца } \\
\cline { 2 - 5 } & ВЭЖХ & СФМ & ВЭХ & $6,90 \pm 0,19$ \\
\hline Вода очищенная & $3,19 \pm 0,10$ & $9,61 \pm 0,18$ & $2,31 \pm 0,05$ & $7,01 \pm 0,15$ \\
Этиловый спирт 40\% & $3,04 \pm 0,05$ & $9,56 \pm 0,20$ & $2,48 \pm 0,07$ & $6,94 \pm 0,16$ \\
Этиловый спирт 70\% & $3,05 \pm 0,08$ & $9,70 \pm 0,16$ & $2,42 \pm 0,10$ & \\
\hline
\end{tabular}

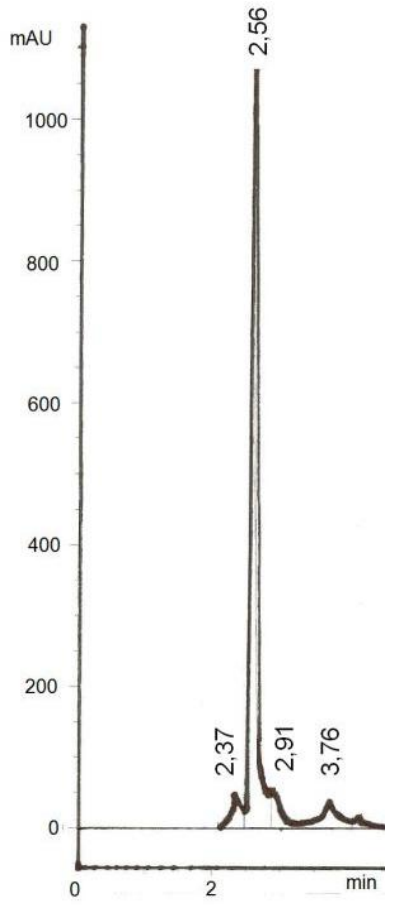

Рис. 4 Хроматограмма элюата сбора

На основании полученных результатов была предложена следующая методика.

Аналитическую пробу сбора измельчают до размера частиц, проходящих сквозь сито с диаметром отверстий 2 мм. Точную навеску сбора (около 2,0 г) помещают в колбу со шлифом вместимостью 250 мл, прибавляют 50 мл 70\%-ного этилового спирта, колбу присоединяют к обратному холодильнику и нагревают при умеренном кипении на водяной бане в течение 30 мин. Извлечение охлаждают под струей холодной воды и фильтруют через бумажный фильтр в мерную колбу вместимостью 100 мл так, чтобы частицы сырья не попадали на фильтр. В колбу для экстрагирования прибавляют 25 мл 70\%-ного этилового спирта и экстракцию повторяют в тех же условиях в течение 20 мин. После охлаждения извлечение фильтруют в ту же мерную колбу. Сырье в колбе дважды промывают порциями по 10 мл этилового спирта 70\% и фильтруют в ту же колбу. Раствор в колбе доводят до метки этиловым спиртом 70\% и перемешивают (раствор А).

50 мл раствора А пропускают через колонку с оксидом алюминия нейтральным для хроматографии. Элюат собирают в круглодонную колбу вместимостью 250 мл. После полного прохождения раствора А колонку дважды промывают порциями по 10 мл 70\%-ного этилового спирта, собирая элюат в ту же колбу. Элюат упаривают на ротационном испарителе досуха и количественно переносят 70\%-ным этиловым спиртом в мерную колбу вместимостью 25 мл (раствор Б). Раствор Б используют для хроматографического определения в условиях, описанных выше.

Содержание арбутина $(\mathrm{X})$ в абсолютно сухом сырье в \% вычисляют по формуле

$$
X=\frac{S_{1} \cdot m_{0} \cdot 100 \cdot 25 \cdot 100 \cdot 100}{S_{0} \cdot m_{1} \cdot 100 \cdot 50 \cdot(100-W)},
$$

где $\mathrm{S}_{1}$ - площадь пика арбутина на хроматограмме испытуемого раствора Б; $\mathrm{S}_{0}$ - площадь пика на хроматограмме раствора ГСО арбутина; $\mathrm{m}$ - масса сырья, в г; $\mathrm{m}_{0}-$ масса навески ГСО арбутина, в г; W - потеря в массе при высушивании сырья, в процентах.

Приготовление хроматографической колонки. 2,0 г оксида алюминия нейтрального для хроматографии, помещают в стеклянную колонку диаметром 1,5 см и высотой 25 см, промывают 10 мл дистиллированной воды, затем 10 мл 70\%-ного этилового спирта. 
Приготовление раствора арбутина. Растворяют 0,05 г (точная навеска) ГСО арбутина, высушенного до постоянной массы при температуре $75 \pm 2{ }^{\circ} \mathrm{C}$, в мерной колбе вместимостью 100 мл в $70 \%$-ном этиловом спирте, доводят объем раствора до метки 70\%-ным этиловым спиртом. Раствор годен в течение 3 суток.

Для проверки воспроизводимости методики определили содержание арбутина в одном и том же образце сбора. Параллельно в этом же образце определили количество арбутина по спектрофотометрической (СФМ) и фармакопейной методике (ГФ ХІ). Как следует из данных, представленных в таблице 2, разработанная методика характеризуется относительно высокой избирательностью и точностью.

Сравнение результатов определения арбутина разными методами показало, что методика спектрофотометрического определения завышает результат определения почти в три раза, методика йодометрического титрования занижает результаты определения на 24\%. В первом случае определению мешают сопутствующие вещества, не задерживающиеся на алюминия оксиде, во втором - причиной, вероятно, является соосаждение арбутина вместе с полигидроксифенольными соединениями ацетатом свинца. Наименьшая величина относительной ошибки отдельного определения $\left(\varepsilon_{1}\right)$ соответствует ВЭЖХ методике $(9 \%)$, наибольшая - СФМ (16\%). Сравнение воспроизводимости методик по критерию Фишера показало с вероятно-

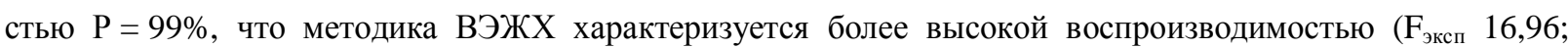
$\left.\mathrm{F}_{\text {табл. }} 8,47\right)$ по сравнению с СФМ методикой и равной воспроизводимостью с фармакопейной методикой $\left(\mathrm{F}_{\text {эксп }} 1,68 ; \mathrm{F}_{\text {табл. }} 8,47\right)$. В большей избирательности ВЭЖХ методики по сравнению со СФМ методикой мы еще раз убедились на следующем этапе исследования. Для обоснования норматива содержания арбутина в сборе было проведено количественное определение арбутина по разработанной методике в 7 опытнопромышленных сериях сбора противооксалатного. Параллельно в этих же сериях сбора оценивалось содержание арбутина по СФМ методике. Результаты представлены в таблице 3.

Обращают на себя внимание не только завышенные результаты при использовании СФМ методики, что уже отмечалось, но и отсутствие корреляции по двум методикам $(\mathrm{r}=0,16)$. Последнее можно объяснить низкой избирательностью СФМ методики.

Данные таблицы 3 также свидетельствуют, что содержание арбутина в разных образцах сбора, найденное методом ВЭЖХ, варьирует от 1,77 до 3,30\%. Как следует из сравнительного анализа таблиц 2 и 3 , значения дисперсий и коэффициентов вариабельности в методике $\left(S^{2}=0,0167 ; \mathrm{V}=4\right)$ и в разных образцах сбора $\left(\mathrm{S}^{2}=0,23 ; \mathrm{V}=21\right)$ существенно различаются, следовательно, методика удовлетворяет аналитическим задачам.

Таблица 2. Содержание арбутина в сборе противооксалатном, найденное разными методами, \%

\begin{tabular}{c|c|c|c}
\hline Содержание и статистиче- & \multicolumn{2}{|c}{ Метод } \\
\cline { 2 - 4 } ские характеристики & ВЭЖХ & СФМ & ГФ ХІ \\
\hline $\bar{X}$ & 3,30 & 9,63 & 6 \\
$\mathrm{n}$ & 6 & 6 & 0,0099 \\
$\mathrm{~S}^{2}$ & 0,0167 & 0,2836 & 0,0997 \\
$\mathrm{~S}$ & 0,1293 & 0,5326 & 0,0407 \\
$\mathrm{~S}_{\mathrm{x}}$ & 0,0528 & 0,2174 & 95 \\
$\mathrm{P} \%$ & 95 & 95 & 0,10 \\
$\Delta \bar{x}$ & 0,14 & 0,56 & 10 \\
$\varepsilon_{1}, \%$ & 9 & 16 & 4,2 \\
$\bar{\varepsilon}, \%$ & 4,1 & 5,8 & 4 \\
$\mathrm{~V}, \%$ & 4 & 6 & \\
\hline
\end{tabular}

Таблица 3. Содержание арбутина в образцах сбора противооксалатного

\begin{tabular}{c|c|c|c}
\hline \multirow{2}{*}{$\begin{array}{c}\text { № } \\
\text { образца }\end{array}$} & \multicolumn{2}{|c|}{$\begin{array}{c}\text { Содержание арбутина } \\
\text { найденное методом, \% }\end{array}$} & $\begin{array}{c}\text { Статистические параметры по выборке образцов, } \\
\text { проанализированных ВЭЖХ методикой }\end{array}$ \\
\cline { 2 - 3 } & ВЭЖХ & СФМ & $\bar{x}=2,32$ \\
2 & 2,40 & 6,54 & $x_{\max }=3,30 \quad x_{\min }=1,77$ \\
3 & 2,03 & 6,65 & $S^{2}=0,23 \quad S=0,48$ \\
4 & 1,77 & 5,54 & $V=21$ \\
6 & 2,39 & 6,23 & \\
7 & 2,22 & 5,46 & \\
\hline
\end{tabular}


Учитывая, что основным источником арбутина в сборе являются листья брусники с его содержанием не менее $4,5 \%$ и доля сырья брусники в сборе составляет $15 \%$, то содержание арбутина, определенного по фармакопейной методике, в сборе должно быть не меньше $0,7 \%$. Если учесть, что методика йодометрического титрования занижает результаты анализов на 24\%, то нижний предел содержания арбутина (ВЭЖХ) в сборе будет составлять $0,9 \%$. Полученное значение подтверждается статистически. В качестве норматива предлагаем установить содержание арбутина в сборе не менее 0,9\%.

\section{Bblводbl}

Проведенные исследования по определению арбутина в сборе противооксалатном показали, что применение для анализа спектрофотометрической и фармакопейной методик дает соответственно завышение и занижение результатов по сравнению с ВЭЖХ методикой.

Выбор оптимальных условий пробоподготовки и хроматографирования позволил предложить относительно избирательную и воспроизводимую методику количественного определения арбутина в сборе противооксалатном.

Экспериментальным и расчетным методом при определении по ВЭЖХ методике обоснован нормативный показатель арбутина в сборе не менее $0,9 \%$.

\section{Список литературь}

1. Патент 2063765 (RU) Сбор для лечения оксалатных нефропатий / Т.А. Степанова, Н.В. Воронина. 1996.

2. Каминская А.В. Фармакогностическое изучение калины Саржента : автореф. дисс. ... канд. фарм. наук. М., 1995. $22 \mathrm{c.}$

3. Волобой Н.Л., Бутакова Л.Ю., Смирнов И.В. Изучение антимикробного действия арбутина и гидрохинона в отношении некоторых представителей грамотрицательной флоры // Химия растительного сырья. 2013 . №1. С. $179-182$.

4. Волобой Н.Л., Зверев Я.Ф., Брюханов В.М., Талалаева О.С., Замятина С.В., Зяблова О.Н., Смирнов И.В. Антиоксидантный и прооксидантный эффекты арбутина и гидрохинона в экспериментах in vitro // Бюллетень сибирской медицины. 2011. Т. 10, №5. С. 41-44.

5. Арльт А.В., Куянцева А.М., Кулешова С.А., Давыдов В.С., Лысенко Т.А., Масликова Г.В., Зацепина Е.Е., Ляхова Н.С., Саркисян К.Х., Чуракова Г.В., Недолуга О.С., Ивашев М.Н. Изучение фармакологического действия биологически активных веществ природного и синтетического происхождения // Разработка, исследование и маркетинг новой фармацевтической продукции. Пятигорск, 2008. С. 376-377.

6. Государственная фармакопея СССР. ХІ изд. М., 1989. Вып. 2. 400 с.

7. Онегин С.В., Меньшов Д.В., Куприянова Н.Е. Разработка методики фотоэлектроколориметрического определения арбутина в лекарственном растительном сырье // Науки о человеке: сб. статей 4-го конгресса молод. ученых. Томск, 2003. С. 214-215.

8. Лубсандоржиева П.Б., Жигжитов Б.С., Даргаева Т.Д., Базарова Ж.Г., Нагаслаева Л.А. Хроматоспектрофотометрическое определение арбутина в листьях Bergenia crassifolia (L.) Fritsch // Химико-фармацевтический журнал. 2000. Т.34, №5. С. 38-40.

9. Китанов Г. Содержание арбутина в Arctostaphylos uva ursi из разных районов НРБ // Растительные ресурсы. 1986. №3. С. $425-428$.

10. Pyka A., Bober K., Stolarczyk A. Densitometric determination of arbutin in cowberry leaves (vaccinium vitis idaeae) // Acta poloniae pharmaceutica - drug research. 2007. Vol. 63, N5. Pp. 395-400.

11. Моисеев Д.В. Определение арбутина в листьях брусники обыкновенной методом ВЭЖХ // Вестник фармации. 2011. №1 (51). С. 40-45.

12. Рылина Е.В. Определение индикаторных фенольных соединений нефлавоноидной природы в лекарственном и пищевом растительном сырье методом ВЭЖХ: автореф. дисс. ... канд. фарм. наук. М., 2010. 24 с.

13. Чукарина Е.В., Власов А.М., Эллер К.И. Определение арбутина и гидрохинона в листьях толокнянки, брусники и фитопрепаратах, приготовленных на их основе // Вопросы питания. 2007. Т. 76, №3. С. 82-87.

14. Федосеева Л.М. Анализ арбутина подземных и надземных вегетативных органов бадана толстолистного (Bergenia crassifolia (L.) Fitsch.), произрастающего на Алтае // Химия растительного сырья. 2003. №1. C. 73-77.

15. Охрименко Л.П., Калинкина Г.И., Дмитрук С.Е. Сравнительное исследование толокнянки, брусники и близких к ним видов, произрастающих в Республике Саха (Якутия) // Химия растительного сырья. 2005 . №1. C. 31-35.

16. Фурса Н.С., Онегин С.В. Содержание арбутина в траве вереска обыкновенного // Фармация. 2007. №6. С. 12-14.

17. Цимбалист Н.А. Фармакогностическое изучение и стандартизация сбора противодиабетического. Фармакогностическое изучение побегов голубики : автореф. дисс. ... канд. фарм. наук. Пермь, 2008. 24 с. 
Zaguzova E.V., Stepanova T.A., Tsimbalist N.A. ${ }^{*}$ TERMINATION OF ARBUTIN IN THE ORIGINAL ANTIOXALATE COLLECTION OF FAR EASTERN MEDICINAL PLANTS

Far Eastern State Medical University, Murav'eva-Amurskogo st., 30, Khabarovsk, 680000 (Russia), e-mail: kfnat@yandex.ru

The article presents the information on the development of methods quantify the arbutin in the antioxalate collection. As a method of arbutin analysis selected high performance liquid chromatography. Widely known methods of determining arbutin - spectrophotometry and iodometry, aren't selective enough for the analysis of herbal medicines, especially those multicomponent as medicine collections.

During the development of HPLC methods experimentally substantiated conditions of sample preparation and chromatography. It was found that as the extractant should be used $70 \%$ ethyl alcohol and purification of the extract rational use of column chromatography on aluminum oxide.

A comparative analysis and statistical evaluation of the results of determination of arbutin on pharmacopeia, spectrophotometric and HPLC methods was carried out. It is shown that the developed method is characterized by a high selectivity, precision, and is suitable for standardization of antioxalate collection by arbutin content.

It was found that the use of spectrophotometric methods overestimates and pharmacopeia methods - underestimates results compared with the original method.

The content of arbutin in pilot series of antioxalate collection was determined by the developed method. Justified normative content of arbutin in antioxalate collection in serial analysis: the amount should not be less than $0.9 \%$.

Keywords: HPLC, arbutin, medicinal collection.

\section{References}

1. Patent 2063765 (RU). 1996. (in Russ.).

2. Kaminskaja A.V. Farmakognosticheskoe izuchenie kaliny Sarzhenta : avtoref. dis. ... kand. farm. [Farmakognostichesky studying Sargent viburnum: dissertation of the candidate of pharmaceutical sciences]. Moscow, 1995, 22 p. (in Russ.).

3. Voloboi N.L., Butakova L.Iu., Smirnov I.V. Khimiia rastitel'nogo syr'ia, 2013, no. 1, pp. 179-182. (in Russ.).

4. Voloboi N.L., Zverev Ia.F., Briukhanov V.M., Talalaeva O.S., Zamiatina S.V., Ziablova O.N., Smirnov I.V. Biulleten' sibirskoi meditsiny, 2011, vol. 10, no. 5, pp. 41-44. (in Russ.).

5. Arl't A.V., Kuiantseva A.M., Kuleshova S.A., Davydov V.S., Lysenko T.A., Maslikova G.V., Zatsepina E.E., Liakhova N.S., Sarkisian K.Kh., Churakova G.V., Nedoluga O.S., Ivashev M.N. Razrabotka, issledovanie i marketing novoi farmatsevticheskoi produktsii. [Development, research and marketing of new pharmaceutical products]. Pyatigorsk, 2008, pp. 376-377. (in Russ.).

6. Gosudarstvennaia Farmakopeia SSSR. [State Pharmacopoeia of the USSR]. XI edition, Moscow, 1989, issue 2, 400 p. (in Russ.).

7. Onegin S.V., Men'shov D.V., Kupriianova N.E. Nauki o cheloveke: cb. statei 4-go kongressa molod. uchenykh. [The science of man: Collection of Articles of 4th congress of young scientists]. Tomsk, 2003, pp. 214-215. (in Russ.).

8. Lubsandorzhieva P.B., Zhigzhitov B.S., Dargaeva T.D., Bazarova Zh.G., Nagaslaeva L.A. Khimikofarmatsevticheskii zhurnal, 2000, vol.34, no. 5, pp. 38-40. (in Russ.).

9. Kitanov G. Rastitel'nye resursy, 1986, no. 3, pp. 425-428. (in Russ.).

10. Pyka A., Bober K., Stolarczyk A. Acta poloniae pharmaceutica - drug research, 2007, vol. 63, no. 5, pp. 395-400.

11. Moiseev D.V. Vestnik farmatsii, 2011, no. 1 (51), pp. 40-45. (in Russ.).

12. Rylina E.V. Opredelenie indikatornykh fenol'nykh soedinenii neflavonoidnoi prirody v lekarstvennom i pishchevom rastitel'nom syr'e metodom VEZhKh: avtoref. diss. ... kand. farm. nauk. [Determination of indicator of phenolic compounds neflavonoidnoy nature in medicinal and food plant material by HPLC: dissertation of the candidate of pharmaceutical sciences]. Moscow, 2010, 24 p. (in Russ.).

13. Chukarina E.V., Vlasov A.M., Eller K.I. Voprosy pitaniia, 2007, vol. 76, no. 3, pp. 82-87. (in Russ.).

14. Fedoseeva L.M. Khimiia rastitel'nogo syr'ia, 2003, no. 1, pp. 73-77. (in Russ.).

15. Okhrimenko L.P., Kalinkina G.I., Dmitruk S.E. Khimiia rastitel'nogo syr'ia, 2005, no. 1, pp. 31-35. (in Russ.).

16. Fursa N.S., Onegin S.V. Farmatsiia, 2007, no. 6, pp. 12-14. (in Russ.).

17. Tsimbalist N.A. Farmakognosticheskoe izuchenie $i$ standartizatsiia sbora protivodiabeticheskogo. Farmakognosticheskoe izuchenie pobegov golubiki : avtoref. dis. ... kand. farm. nauk. [Farmakognostichesky studying and standardization of the collection of anti-diabetic. Farmakognostichesky studying shoots blueberry: dissertation of the candidate of pharmaceutical sciences]. Perm, 2008, 24 p. (in Russ.).

Received October 15, 2014

Revised May 7, 2015

\footnotetext{
* Corresponding author.
} 
